\title{
Extremities Fracture and Associated Factors among Adult Patients in Debre Markos Referral Hospital, East Gojjam Zone, Northern Ethiopia: A Hospital Based Cross-Sectional Study
}

\author{
Yoseph Merkeb Alamneh ${ }^{1 *}$, Getachew Chane ${ }^{2}$, Mengistu Ayele ${ }^{2}$ and \\ Asfaw Gerbi² \\ ${ }^{1}$ Department of Biomedical Sciences, School of Medicine, Debre Markos University, \\ Debre, Markos, Ethiopia \\ ${ }^{2}$ Department of Biomedical Sciences, Institute of Health Science, Jimma University, \\ Jimma, Ethiopia \\ *Corresponding Author: Yoseph Merkeb Alamneh, Department of Biomedical \\ Sciences, School of Medicine, Debre Markos University, Debre, Markos, Ethiopia.
}

Received: July 30, 2020

Published: August 24, 2020

(C) All rights are reserved by Yoseph Merkeb Alamneh., et al.

\begin{abstract}
Background: Extremities' fractures, particularly when left untreated, are a common sequelae of injuries and a major cause of morbidity and mortality; but the burden and distribution of traumatic fractures in low- and middle-income countries is poorly understood. The increasing the prevalence of extremity fracture can be attributed to modernization, industrialization and increased rate of bone fracture in the society. Extremities fracture is the leading cause of functional disability and death in different age groups in both sex. It may result from road traffic accidents, falls, gunshot, machines, attacks as well as sports. The epidemiology of fracture in Ethiopia provides little knowledge about its distribution and associated factors needed for prevention. Thus, this study aimed to investigate extremities fracture and associated factors in Debre Markos referral Hospital.Hypermobility of the knee can predispose early osteoarthritis in this age group of military personnel moreover due to repetitive stress and prolonged standing in static posture, ligament or tendon injury, bone contusion and stress fracture may occur.

Methods: Hospital based cross-sectional study was conducted from April to June 2018 at Debre Markos referral hospital, Northern Ethiopia. A total of 422 patients were included in this study. Data were collected using a structured questionnaire by trained data collectors. The collected data were coded, entered into epi data 3.1, and exported to STATA version 14 for statistical analysis. Simple logistic Regression analysis and Multiple logistic regression analyses was employed to identify factors associated with extremity fracture and factors which had a p-value of $\leq 0.25$ in Simple Logistic Regression analysis was included in Multiple Logistics Regression analysis. P-values of less than or equal to 0.05 was considered statistically significant.

Result: Among the total 422 adult patients who visited the emergency department, 144 (34.12\%) patients experienced extremity fractures in Debre Markos Referral Hospital. Ninety-two (63.9\%) were males and 52(36.1\%) were females and their age range from 26 to 77 years. Residency, sex, age, behavioral factors such as using alcohol and fighting, vehicle type, types of occupation and medical illness were identified as the key risk factors of extremities fracture.

Conclusion and Recommendation: The prevalence of extremities fracture were high at study area and socio-demographic characteristics, behavioral factors and co-morbidities were found to be significantly associated with extremity fracture. Therefore, efforts should be scaled up to develop effective preventive measures and enforced against fractures of extremities.

Keywords: Fracture; Adults; Risk Factors; Ethiopia
\end{abstract}

Citation: Yoseph Merkeb Alamneh., et al. "Extremities Fracture and Associated Factors among Adult Patients in Debre Markos Referral Hospital, East Gojjam Zone, Northern Ethiopia: A Hospital Based Cross-Sectional Study”. Acta Scientific Orthopaedics 3.9 (2020): 18-29. 


\section{Abbreviations}

AOR: Adjusted Odds Ratio; CI: Confidence Interval; COR: Crude Odd Ratio; DMRH: Debre Markos Referral Hospital; RTA: Road Traffic Accident

\section{Background}

Fractures are the most common encountering injury at the orthopaedic and emergency department in developed and developing countries [1]. Fracture can be occurred due to different causes and under a variety of clinical circumstances and most commonly, it is the result of a force acting on normal bone and disrupting the normal bony architecture [2]. It is considered as a leading cause of death and disability for people under 45 years. However, the prevalence of extremity fracture are declining in developed countries [3]. Injury-related bone fracture contributes to an increase in morbidity, death, disability, and health expenditures across the age span.

Worldwide, musculoskeletal injuries and associated with long bone fracture are global health burden and accounts significant morbidity and mortality [4]. The global burden of disease (GBD 2010 ) estimated that the global death due to injuries rise from $8.8 \%$ to $9.6 \%$ in the last two decades [5]. Nationally, extremity fracture projected to increase from 2.1 million to 3.0 million from 2005 to 2025 [6]. In both developed and developing countries road traffic accident is the main causes of traumatic fracture in adults [7]. In Africa, the commonest injuries were fracture (69.0\%) and the most affected age group was 15-44 years (81.9\%) [8]. Almost all fracture related researches have focused on fracture of long bones of extremity, however, other fracture in extremities are becoming common [9]. There are different determinants of fracture including age, race, sex, biology, physiology, body habitus, environmental exposure to fracture-producing injury mechanisms and access to prevention programs [10]. The incidence of fracture varies in sex and age groups, but within similar age group the proportion of fracture in both sex had similar distribution [11]. Concerning in the study area no previous study was done in extremity fractures.

As a result, the findings of this study will help to identify potential risk factors of extremity fracture, and individuals who are more likely at risk of extremity fracture; addressing those risk factors may help to design strategies to reduce extremity fracture. Therefore, the purpose of this study was to investigate the prevalence and associated factors of extremity fracture. This study will provide baseline information on the same issue in Debre Markos referral Hospital.

\section{Method and participants}

Hospital based cross-sectional study design was conducted among all adult patients who were attending at surgical ward and orthopedic Emergency department. The study subjects were all patients who have extremities fracture diagnosed, their age 18+ years and voluntary to participate was included in this study. Patients' age less than 18 years and critical ill patients, incomplete information on their card were excluded in this study. The sample size was estimated based on a single population proportion (p) formula: $n$ $=(\mathrm{Z} \alpha / 2)^{2} \mathrm{P}(1-\mathrm{P}) /(\mathrm{d})^{2}$. Where $\mathrm{n}$ is sample size, $\mathrm{p}$ is the sample proportion, and $d$ is the margin of error. The following assumptions were used. Since there is no local data available for the value of $\mathrm{P}$, was taken to be $50 \%(\mathrm{P}=0.5)$ to allow the maximum sample size. Allowing 5\% for an expected margin of error (d) and 95\% confidence interval, the required sample size $\mathrm{n}$ was 384 . With a $10 \%$ non-response rate, the total sample size was 422 .

Consecutive sampling technique was used based on the availability Patients, who have extremities fractures, coming to the hospital during the study period, April to June 2018. Two data collectors (BSc nurses) and one supervisor was assigned. The data were collected by nurses working in the hospital who were trained on data collection tools for two days and the data collection process was supervised by the supervisor in order to maintain the quality of the data. Data were collected using a structured questionnaire. The collected data were coded, entered into epi data 3.1, and exported to STATA version 14 for statistical analysis. Simple logistic Regression analysis and Multiple logistic regression analyses was employed, and factors which had a p-value of $\leq 0.25$ in Simple Logistic Regression analysis was included in Multiple Logistics Regression analysis. P-values of less than or equal to 0.05 was considered statistically significant. The study protocol was approved and ethically cleared by Health Research Review Board of Jimma University. Official letter of co-operation was written to Debre Markos Referral Hospital from JUIH and letter of permission was sent to Debre Markos Referral Hospital. In order to protect the confidentiality of the information, personal identifiers such as names were not used during the data collection analysis and reporting of findings.

\section{Results}

\section{Sociodemographic characteristics of respondents}

Among the total 422 adult patients who visited the emergency department, 144 (34.12\%) patients experienced extremity fractures in Debre Markos Referral Hospital. Out of 144 patients $92(63.9 \%)$ were males and $52(36.1 \%)$ were females. The respondents found in age group from 26 to 77years (mean $=52.19$ and $S D=10.90)$. Concerning place of resident of the respondents $55(38.2 \%)$ and $89(61.8 \%)$ were lived in urban and rural respectively (Table 1). 
Extremities Fracture and Associated Factors among Adult Patients in Debre Markos Referral Hospital, East Gojjam Zone, Northern Ethiopia: A Hospital Based Cross-Sectional Study

Table 1: Sociodemographic characteristics of the participants, Debre Markos referral Hospital, East Gojjam Zone, Northern Ethiopia, 2018.

\begin{tabular}{|c|c|c|}
\hline Variables & Categories & n (\%) \\
\hline \multirow[t]{2}{*}{ Sex } & Male & $92(63.9)$ \\
\hline & Female & $52(36.1)$ \\
\hline \multirow[t]{2}{*}{ Religions } & Orthodox & $120(83.3)$ \\
\hline & Muslim & $24(16.7)$ \\
\hline \multirow[t]{3}{*}{ Ethnicity } & Amhara & $113(78.5)$ \\
\hline & Oromo & $16(11.1)$ \\
\hline & Tigray & $15(10.4)$ \\
\hline \multirow[t]{4}{*}{ Marital status } & Single & $20(13.9)$ \\
\hline & Married & $85(59.0)$ \\
\hline & Divorced & $23(16.0)$ \\
\hline & Widowed & $16(11.1)$ \\
\hline \multirow{5}{*}{$\begin{array}{l}\text { Educational } \\
\text { status }\end{array}$} & No formal education & $47(32.6)$ \\
\hline & Elementary & $32(22.2)$ \\
\hline & High school & $18(12.5)$ \\
\hline & Preparatory & $16(11.1)$ \\
\hline & College and above & $31(21.5)$ \\
\hline \multirow[t]{8}{*}{ Occupation } & Governmental employee & $15(10.4)$ \\
\hline & Farmer & $32(22.2)$ \\
\hline & Merchant & $18(12.5)$ \\
\hline & House wife & $13(9.0)$ \\
\hline & Daily labor & $16(11.1)$ \\
\hline & Student & $13(9.0)$ \\
\hline & Unemployed & $14(9.7)$ \\
\hline & $\begin{array}{l}\text { Other (drivers and } \\
\text { construction workers) }\end{array}$ & $23(16.0)$ \\
\hline
\end{tabular}

\section{Prevalence of fracture by age and sex}

About 45(68.2\%) and 21(31.8\%) males and females' patients had upper extremity fractures. About 48(68.6\%) and 22(31.4\%) males and females' patients had lower extremity fracture respectively. About $8(0.6 \%)$ patients had both extremities fractures. About $77.8 \%$ and $56.8 \%$ of extremity fracture occurred in age group 40 - 50 years and above 72 years in male and female respectively (Figure 1).

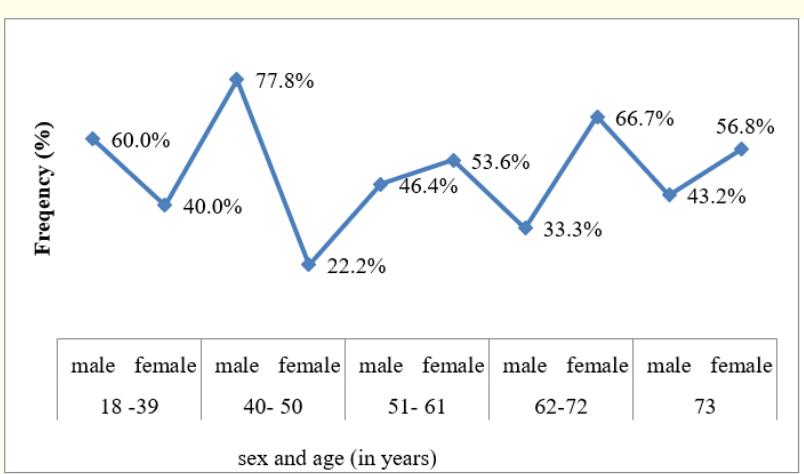

Figure 1: Prevalence of extremity fractures by age and sex among adult patients in Debre Markos referral hospital, East Gojjam Zone, Northern Ethiopia, 2018.

\section{Type of bones fractured}

Concerning to type of bone fractured in upper and lower limbs were almost equal proportions $66(45.8 \%)$ and 70 (48.6\%) respectively. It was also identified that the fracture was either single or multiple at different sites. In the upper extremities, the majorities of fracture occurred in the phalanges $18(12 \%)$, ulna $12(8.3 \%)$ followed by proximal humerus $8(5.6 \%)$, proximal radius $8(5.6 \%)$

\begin{tabular}{|c|c|c|}
\hline Variables & Specific sites & n (\%) \\
\hline \multirow[t]{3}{*}{ Humerus } & Proximal & $8(5.6)$ \\
\hline & Inta-Articular & $2(1.4)$ \\
\hline & Multiple & $2(1.4)$ \\
\hline \multirow[t]{3}{*}{ Radius } & Proximal & $8(5.6)$ \\
\hline & Midshaft & $4(2.8)$ \\
\hline & Multiple & $2(1.4)$ \\
\hline \multirow[t]{3}{*}{ Ulnar } & Midshaft & $2(1.4)$ \\
\hline & Distal & $12(8.3)$ \\
\hline & Multiple & $2(1.4)$ \\
\hline \multirow[t]{4}{*}{ Radioulna } & Proximal & $2(1.4)$ \\
\hline & Midshaft & $2(1.4)$ \\
\hline & Distal & $4(2.8)$ \\
\hline & Multiple & $2(1.4)$ \\
\hline \multirow{7}{*}{$\begin{array}{l}\text { Carpal } \\
\text { Metacarpal }\end{array}$} & Scaphoid & $6(4.2)$ \\
\hline & Multifocal & $2(1.4)$ \\
\hline & First & $2(1.4)$ \\
\hline & Second & $2(1.4)$ \\
\hline & Fourth & $1(.7)$ \\
\hline & Fifth & $1(.7)$ \\
\hline & Multiple & $2(1.4)$ \\
\hline
\end{tabular}


Extremities Fracture and Associated Factors among Adult Patients in Debre Markos Referral Hospital, East Gojjam Zone, Northern Ethiopia: A Hospital Based Cross-Sectional Study

\begin{tabular}{|c|c|c|c|c|c|c|}
\hline \multirow[t]{6}{*}{ Phalanges } & First & $3(2.1)$ & \multirow[t]{2}{*}{ Pelvic } & \multicolumn{2}{|l|}{ Pubic } & \multirow{2}{*}{$\begin{array}{l}14(9.7) \\
2(1.4)\end{array}$} \\
\hline & Second & $2(1.4)$ & & \multicolumn{2}{|l|}{ Combined } & \\
\hline & Third & $4(2.8)$ & \multirow{4}{*}{\multicolumn{4}{|c|}{$\begin{array}{l}\text { Table } 2 \text { : Type of bone fractured among adult patients in Debre } \\
\text { Markos referral hospital, East Gojjam Zone, Northern Ethiopia, } \\
2018 .\end{array}$}} \\
\hline & Fourth & $4(2.8)$ & & & & \\
\hline & Fifth & $3(2.1)$ & & & & \\
\hline & Multiple & $2(1.4)$ & & & & \\
\hline \multirow[t]{3}{*}{ Clavicle } & Outer Third & $4(2.8)$ & \multirow{12}{*}{\multicolumn{4}{|c|}{$\begin{array}{l}\text { Distribution of fracture by anatomical sites and sex } \\
\text { Concerning to distribution of bone fractured by anatomical si } \\
\text { and sex in upper and lower limbs were almost equal proportic } \\
66(45.8 \%) \text { and } 70(48.6 \%) \text { respectively and based on sex site } \\
\text { fracture were phalanges } 15(16.4 \%) \text { in males, humerus } 7(13.4 \%) \\
\text { females and femur } 12(13 \%) \text { in males, pelvic } 10(19.2 \%) \text { in fema } \\
\text { in upper and lower extremities respectively. It was also identif } \\
\text { that the fracture was either single or multiple at different sites. } \\
\text { the lower extremities (in both sex), the majorities of fracture } \\
\text { curred in the femur } 20(14 \%) \text {, patella } 18(12.6 \%) \text {, and tibiofibu } \\
16(11.2) .18(12 \%) \text { respectively as shown in (Table } 3) \text {. }\end{array}$}} \\
\hline & Middle Third & $4(2.8)$ & & & & \\
\hline & Multiple & $2(1.4)$ & & & & \\
\hline \multirow[t]{4}{*}{ Scapula } & Body & $2(1.4)$ & & & & \\
\hline & Spine & $2(1.4)$ & & & & \\
\hline & Acromion & $4(2.8)$ & & & & \\
\hline & Multiple & $2(1.4)$ & & & & \\
\hline \multirow[t]{5}{*}{ Femur } & Proximal & $6(4.2)$ & & & & \\
\hline & Midshaft & $2(1.4)$ & & & & \\
\hline & Distal & $8(5.6)$ & & & & \\
\hline & Inta-Articular & $2(1.4)$ & & & & \\
\hline & Multiple & $2(1.4)$ & & & & \\
\hline \multirow[t]{3}{*}{ Tibia } & Distal & $2(1.4)$ & \multirow{3}{*}{$\begin{array}{l}\text { Anatomic } \\
\quad \text { site } \\
\text { (variables) }\end{array}$} & \multirow{3}{*}{ Specific sites } & \multicolumn{2}{|c|}{ Sex of the respondents } \\
\hline & Intra articular & $2(1.4)$ & & & Male & Female \\
\hline & Multiple & $2(1.4)$ & & & n (\%) & n (\%) \\
\hline \multirow[t]{4}{*}{ Fibula } & Midshaft & $2(1.4)$ & \multirow[t]{3}{*}{ Humerus } & Proximal & $3(3.3)$ & $5(9.6)$ \\
\hline & Distal & $8(5.6)$ & & Inta-Articular & $2(2.2)$ & - \\
\hline & Inta-Articular & $2(1.4)$ & & Multiple & - & $2(3.8)$ \\
\hline & Multiple & $2(1.4)$ & \multirow[t]{6}{*}{ Radius } & Proximal & $6(6.5)$ & $2(3.8)$ \\
\hline \multirow[t]{4}{*}{ Tibiofibular } & Proximal & $8(5.6)$ & & Midshaft & $2(2.2)$ & $2(3.8)$ \\
\hline & Midshaft & $4(2.8)$ & & Multiple & - & $2(3.8)$ \\
\hline & Distal & $2(1.4)$ & & Midshaft & - & $2(3.8)$ \\
\hline & Multiple & $2(1.4)$ & & Distal & $10(10.9)$ & $2(3.8)$ \\
\hline \multirow[t]{4}{*}{ Patella } & Vertical & $8(5.6)$ & & Multiple & - & $2(3.8)$ \\
\hline & Tranverse & $4(2.8)$ & \multirow[t]{4}{*}{ Radio ulna } & Proximal & $2(2.2)$ & - \\
\hline & Distal pole & $4(2.8)$ & & Midshaft & $2(2.2)$ & - \\
\hline & Multiple & $2(1.4)$ & & Distal & $4(4.3)$ & - \\
\hline \multirow[t]{3}{*}{ Ankle } & Lateral malleolus & $4(2.8)$ & & Multiple & & $2(3.8)$ \\
\hline & Media Malleolus & $2(1.4)$ & \multirow[t]{2}{*}{ Carpal } & Scaphoid & $6(6.5)$ & - \\
\hline & Multiple & $2(1.4)$ & & Multifocal & - & $2(3.8)$ \\
\hline \multirow[t]{3}{*}{ Tarsal } & Tarsus & $4(2.8)$ & \multirow[t]{5}{*}{ Metacarpal } & First & $2(2.2)$ & - \\
\hline & Navicular & $2(1.4)$ & & Second & $2(2.2)$ & - \\
\hline & Cuboid & $2(1.4)$ & & Fourth & $1(1.1)$ & - \\
\hline Metatarsal & Multiple & $4(2.8)$ & & Fifth & $1(1.1)$ & - \\
\hline Phalanges & Multiple & $4(2.8)$ & & Multiple & & $2(3.8)$ \\
\hline
\end{tabular}


Extremities Fracture and Associated Factors among Adult Patients in Debre Markos Referral Hospital, East Gojjam Zone, Northern Ethiopia: A Hospital Based Cross-Sectional Study

\begin{tabular}{|c|c|c|c|c|c|c|c|}
\hline \multirow[t]{3}{*}{ Pharynges } & First & $3(3.3)$ & - & Phalanges & Multiple & $2(2.2)$ & $2(3.8)$ \\
\hline & Second & $2(2.2)$ & - & \multirow[t]{2}{*}{ Pelvic } & Pubic & $6(6.5)$ & 8 (15.4) \\
\hline & Third & $3(3.3)$ & $1(1.9)$ & & Combined & - & $2(3.8)$ \\
\hline
\end{tabular}

Table 3: Distribution of fracture by anatomic sites and sex among adult patients in Debre Markos referral hospital, East Gojjam Zone, Northern Ethiopia, 2018.

Fracture prevalence by fracture mechanisms and locations

Several causes responsible as to the etiology of fracture from traumatic to none traumatic factors were identified and nearly all the fracture $132(91.7 \%)$ were due to traumatic incidents but only $12(8.3 \%)$ were due to non-traumatic (pathological) fracture. Road traffic accident constitutes the largest proportion, 30(20.8\%), among traumatic causes followed by fall down accident $23(16.0 \%)$ and hit by stick 22(15.3\%). RTA (travelers and pedestrians) $30(20.8 \%)$ of which $70 \%$ and $30 \%$ occurred in urban and rural respectively (Figure 2).

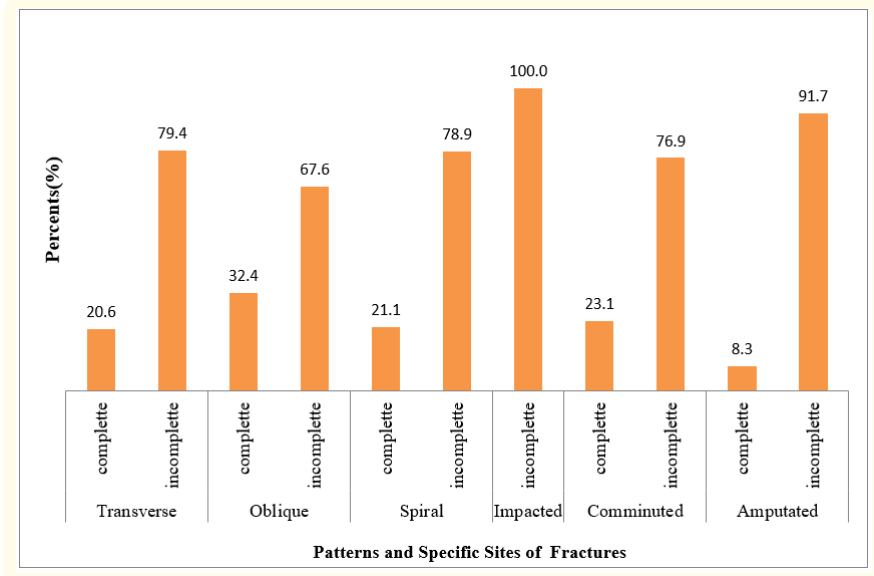

Figure 2: Pattern and specific site of fractures among adult patients in Debre Markos referral hospital, East Gojjam Zone, Northern Ethiopia, 2018.

\section{Nature of fracture}

About 76(52.8\%) and 68(47.2\%) patients had open and closed extremity fracture respectively (Figure 3).

\section{Pattern and specific site of fracture of adult limbs fractures}

Regard to patterns of fracture about $114(79.2 \%)$ and $30(20.8 \%)$ of patients had incomplete and complete fractures. The most com- 


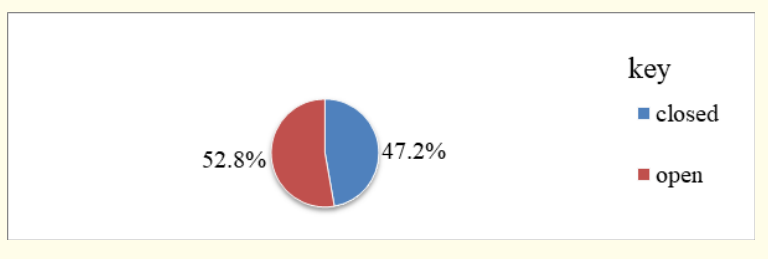

Figure 3: Nature of fractures among adult patients in Debre Markos referral hospital, East Gojjam Zone, Northern Ethiopia, 2018.

mon specific sites of fracture were oblique $37(25 \%)$, transverse $34(23.6 \%)$ and comminuted $26(18.1 \%)$.

Among oblique fracture about $67.6 \%$ and $32.4 \%$ were incomplete and complete fracture respectively.

\section{Associated factors of extremity fracture}

\section{Patient related factors and demographic factors}

Sociodemographic characteristics such as sex and age had an association with extremity fractures. As age increases the prevalence of extremity fracture increases. This study showed that the highest age group mostly affected was between 40 to 50 years $(77.8 \%)$ and 62 to 72 years $(66.7 \%)$ in males and females respectively.

\section{Injury mechanisms and behavioral factors}

The majority of the cause of extremity fracture was RTA (20.8\%). This had related with behavioral factors of the victim and the results showed that among the respondents who had behavioral factors such as using alcohol and fighting was 55\% and 23\% respectively.

\section{Environmental and vehicle related factors}

The majority of the respondents came from rural (61.1\%) and among RTA, vehicle types were Isuzu and Bajaj, $11.1 \%$ and $9.7 \%$ respectively. This result showed that extremity fracture is more common in rural than urban and Isuzu was the commonest cause of RTA.

Individual factors associated with extremity fracture in binary logistic regression

To identify associated factors of extremity fracture among patients, binary logistic regression was computed. Those variables with P-value $<0.25$ in bivariate analysis were entered into multivariate analysis using multiple logistic regressions in order to control confounders and to predict factors associated with extremity fracture at $p$ value less than 0.05 . This study showed that as the age increases the prevalence of extremity fracture also increase in both sexes. The findings showed that Sociodemographic characteristics can be the risk factors for extremity fractures. As a result, about $32(22.2 \%)$ respondents were farmers and followed by construction workers $23(16.6 \%)$ and daily labors $16(11.1 \%)$ respectively. As the study showed that about $40(60 \%)$ had experienced in closed fractures. In addition, behavioral factors can be attributed for extremity fractures. Besides, the location of the accidents had a contribution for fractures. Therefore, about 36(54.5\%) and $30(45.5 \%)$ the accident was occurred in rural and urban respectively. Moreover, other medical illness had also the risk factors for the prevalence of the fractures (Table 4 and Table 5).

Factors associated with extremity fractures in multivariable logistic regression

Variables which were significant in the first model $(\mathrm{p}<0.25)$ were taken and analyzed together by multivariable logistic regression in order to predict factors associated with substance use at a $\mathrm{p}$ value less than 0.05 . Therefore, being the remaining variables constant, being farmer the probability of having lower extremity fractures was decreased by the odds of 0.114 times (AOR [ $95 \%$ CI] $0.114(0.025,0.509)$ as compare to being construction workers. With other variables making constant, being government employer, merchant, house wife, students, and unemployed the chance of having extremity fractures were decreased by the odds of 0.034 times (AOR [95\% $175 \mathrm{CI}] 0.034(0.004,0.298), 0.083$ times (AOR [95\% CI] 0.083(0.014, 0.486), 0.131times (AOR [95\% $176 \mathrm{CI}]$ $0.92(0.015,0.572), 0.131$ times (AOR [95\% CI] 0.131(0.021, 0.815) and 0.077 times (AOR [95\% CI] $0.077(0.011,0.540)$ as compare to being construction workers. Patients who had behavioral factors (using alcohol and fighting) chance of fracture was increased by the odds of 3.911 times (AOR [95\% CI] 3.911(1.473, 10.384) as compared to those who had no behavioral factors. Patients who used alcohol and had fighting behavior the chance of extremity fractures were increased by the odds of 2.989 times (AOR [95\% CI] $2.989(1.408,6.348)$ and 3.725 times (AOR [95\% CI] 3.725(1.319, 10.524) respectively. Being urban the chance of fractures was decreased by $54 \%$ as compared being rural. The probability of open fractures in upper extremity were decreased by the odds of 0.346 times (AOR [95\% CI] $0.346(0.185,0.716)$ as compared to closed fractures. The chances of upper extremity fractures in patients who had no behavioral factors (alcohol using and fighting) were decreased by the odds of 0.371 times (AOR [955 CI] 0.371(0.177, 0.776 ) as compared to patients who had no behavioral factors. The probability of the occurrence of fractures in rural were more likely 2.491 times (AOR [95\% CI] 2.491(1.160, 5.347) as compare to urban (Table 6 and table 7). 
Extremities Fracture and Associated Factors among Adult Patients in Debre Markos Referral Hospital, East Gojjam Zone, Northern Ethiopia: A Hospital Based Cross-Sectional Study

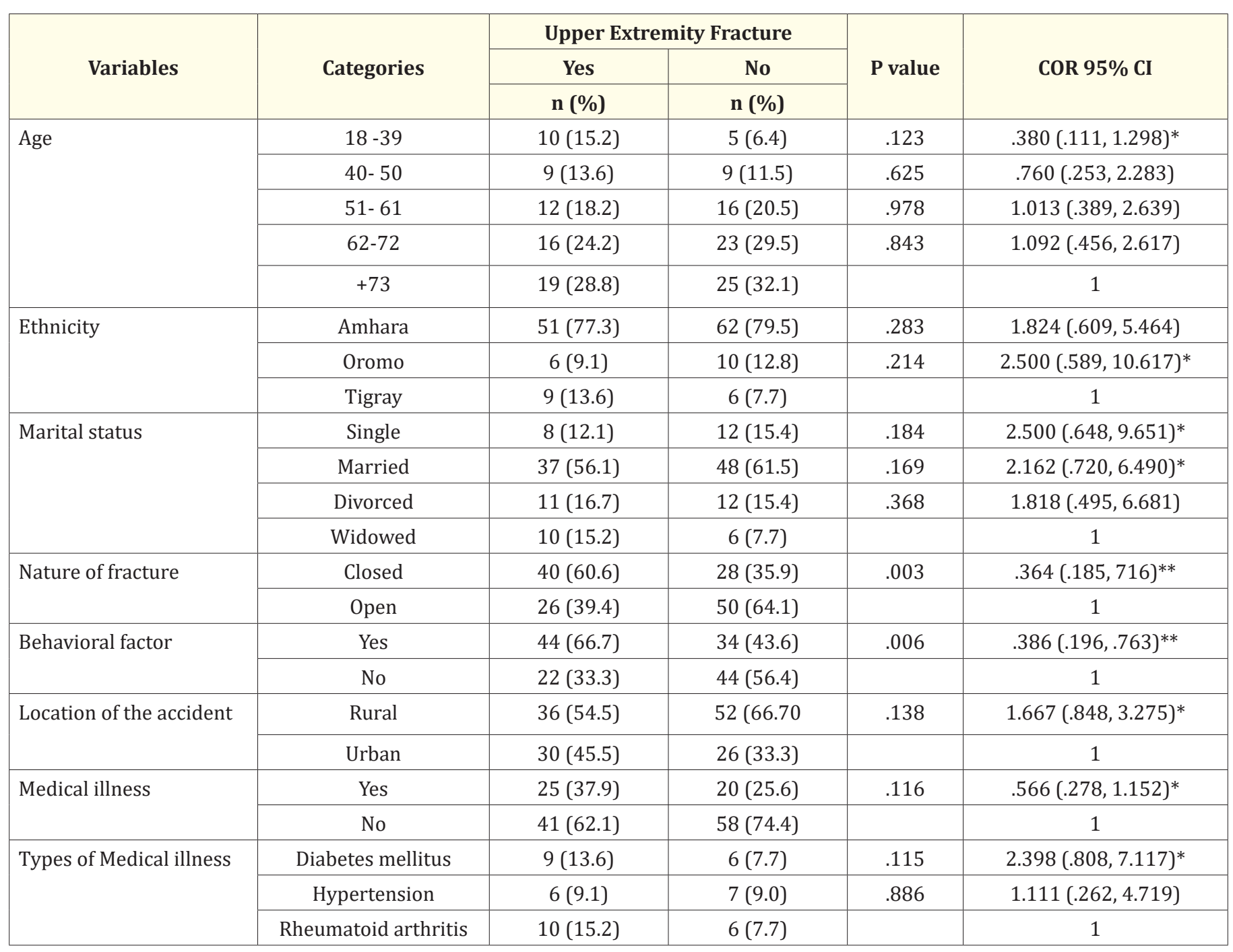

Table 4: Binary logistic regression of individuals factors of the respondents for upper extremity fracture among adult patients in Debre Markos referral hospital, East Gojjam Zone, Northern Ethiopia, 2018.

Abbreviations: COR: Crude Odd Ratio; CI: Confidence Interval. Significant *, P-value <0.25, Statically significant **; P-value < 0.05.

\begin{tabular}{|c|c|c|c|c|c|}
\hline \multirow{3}{*}{ Variables } & \multirow{3}{*}{ Categories } & \multicolumn{2}{|c|}{ Lower Extremity Fractures } & \multirow{3}{*}{ P values } & \multirow{3}{*}{ COR 95\% CI } \\
\hline & & Yes & No & & \\
\hline & & n (\%) & n (\%) & & \\
\hline Sex & Female & $22(31.4)$ & $30(40.5)$ & & 1 \\
\hline \multirow[t]{4}{*}{ Age } & $18-39$ & $8(11.4)$ & $7(9.5)$ & .252 & $.500(.153,1.637)$ \\
\hline & $51-61$ & $15(21.4)$ & $13(17.6)$ & .153 & $.495(.189,1.298)^{*}$ \\
\hline & $62-72$ & $22(31.4)$ & $17(23.0)$ & .069 & $.442(.183,1.067)^{*}$ \\
\hline & +73 & $16(22.9)$ & $28(37.8)$ & & 1 \\
\hline
\end{tabular}


Extremities Fracture and Associated Factors among Adult Patients in Debre Markos Referral Hospital, East Gojjam Zone, Northern Ethiopia: A Hospital Based Cross-Sectional Study

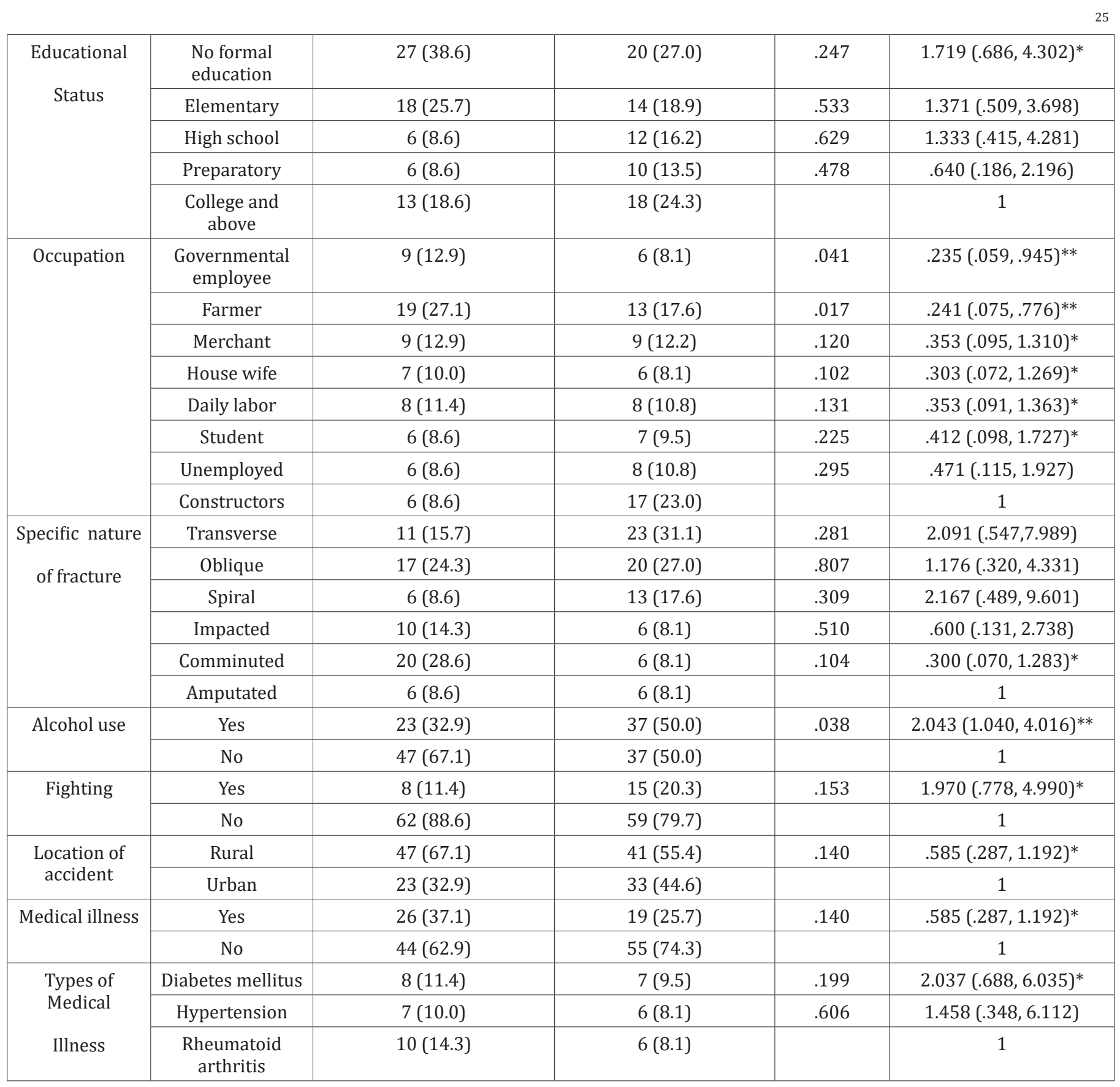

Table 5: Binary logistic regression of individuals factors of the respondents for lower extremity fracture among adult patients in Debre Markos referral hospital, East Gojjam Zone, Northern Ethiopia, 2018.

Abbreviations: COR: Crude Odd Ratio; CI: Confidence Interval. Significant *, P-value <0.25, Statically significant **; P-value < 0.05. 
Extremities Fracture and Associated Factors among Adult Patients in Debre Markos Referral Hospital, East Gojjam Zone, Northern Ethiopia: A Hospital Based Cross-Sectional Study

26

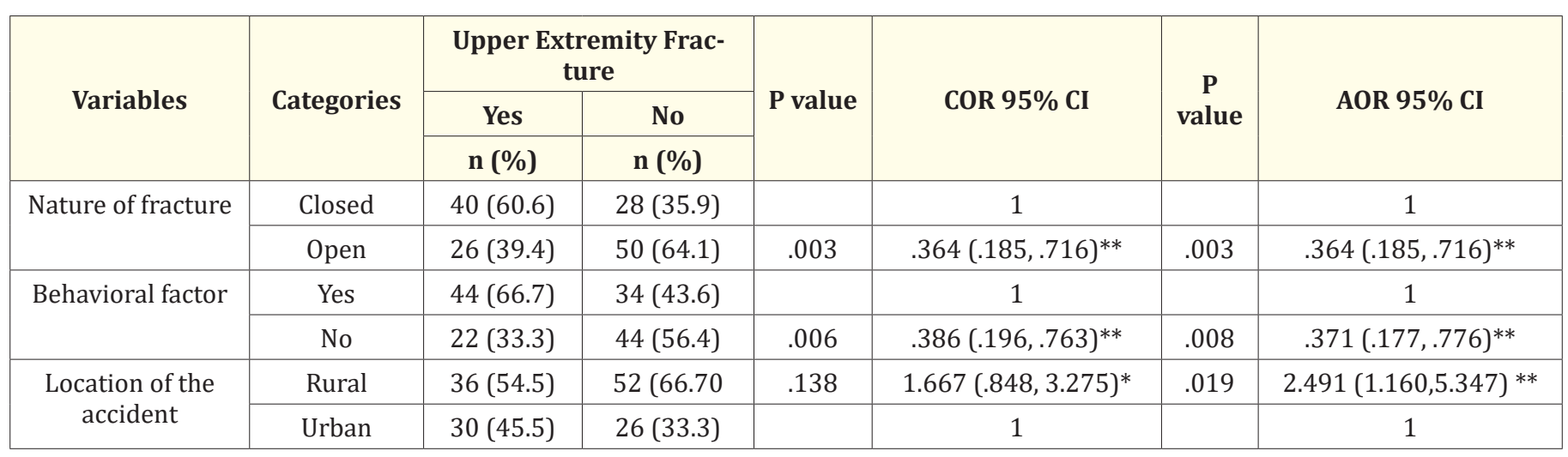

Table 6: Multiple logistic regression of individuals factors of the respondents for upper extremity fracture among adult patients in Debre Markos referral hospital, East Gojjam Zone, Northern Ethiopia, 2018.

Abbreviations: COR: Crude Odd Ratio; CI: Confidence Interval. Significant *, P-value $<0.25$, Statically significant **; P-value $<0.05$.

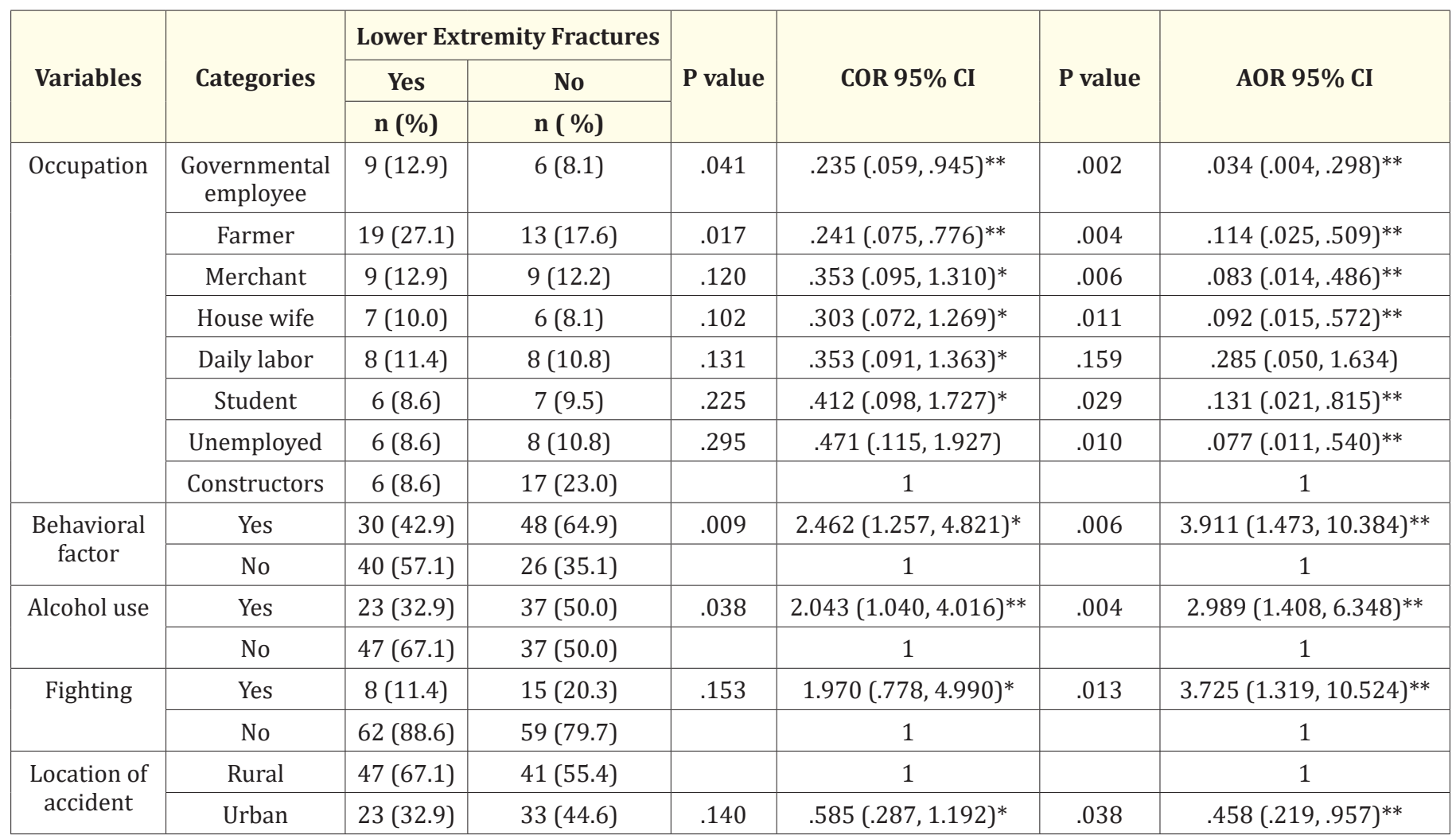

Table 7: Multiple logistic regression of individuals factors of the respondents for lower extremity fracture among adult patients in Debre Markos referral hospital, East Gojjam Zone, Northern Ethiopia, 2018.

Abbreviations: COR: Crude Odd Ratio; CI: Confidence Interval. Significant*, P-value $<0.25$, Statically significant **; P-value $<0$. 


\section{Discussion}

Currently, adult extremity fractures are a driving cause of morbidity and mortality in low- and middle-income countries including Ethiopia. The purpose of the study was conducted to assess Extremities fracture and associated factors among adult patients in Debre Markos hospital. As far as our knowledge, there is no previous studies of the issue. Hence, assessing prevalence and its risk factors of extremity fractures are essential for proper planning of health care services, for proper management and prevention strategy in the study area. In this study about $77.8 \%$ and $56.8 \%$ of extremity fracture occurred in age group 40 - 50 years and above 72 years in male and female respectively. Socio-demographic characteristics such as sex, age, occupation, location and behavioral factors such as drinking alcohol and fighting had an association with extremity fractures.

The study revealed that $16(11.1 \%)$ were daily laborer, $13(9.0 \%)$ house wife, 32(22.2\%) farmers, $13(9.0 \%)$ students, $15(10.4 \%)$ civil servants, 18(12.5\%) merchants, 14(9.7\%) unemployed, and $23(16 \%)$ drivers and construction workers. Other study done in Addis Ababa revealed that $21.5 \%$ were daily laborers, $15.4 \%$ house wives, $12.6 \%$ farmers, $12.6 \%$ students, $10.9 \%$ civil servants, $5.2 \%$ merchants, $4.8 \%$ drivers and others $17 \%$ by occupation [12]. This difference may be due to occupational difference in the compared area and the study area.

This study showed that being government employer, merchant, house wife, students, and unemployed the chance of having extremity fracture were decreased by the odds of 0.034 times (AOR [ $95 \%$ CI] 0.034(0.004, 0.298), 0.083 times (AOR [95\% CI] 0.083(0.014, $0.486), 0.131$ times (AOR [95\% CI] 0.92(0.015, 0.572), 0.131 times (AOR [95\% CI] 0.131(0.021, 0.815) and 0.077 times (AOR [95\% CI] $0.077(0.011,0.540)$ as compare to being construction workers. This might be due to being construction workers are at risk of injury and falling that causes fractures. This is due to the various emotional, physical and social consequences of employees who work overtime hours. Significant effects could also be reduced including stress, lack of free time, poor work-life balance, health risks and levels of employee performance. Long working hours could also lead to fatigue tiredness and lack of attention [13].

A study done in Edinburgh, showed that incidence of fracture were higher in men than women in all age groups from 15 to 49 years [14]. In line with this study done in Addis Ababa revealed that the highest age group mostly affected was between 21-30 year,
$36.5 \%$ and the highest peak of male to female ratio occurred in the age group between 31 to 40 years which was 5.2: 1 [12]. But in this study, about $77.8 \%$ and $56.8 \%$ of extremity fracture occurred in age group 40 - 50 years and above 72 years in male and female respectively. This is may be due to high occupational difference that cause fracture in the study area and males are mainly participating in physical works like construction and outdoor activities. Other possible explanations may be lack of the use of PPE will reduce exposure to hazards that cause serious injury to the workplace that may result from association with chemical, radiological, physical, electrical, mechanical or other hazards in the workplace.

The study done in United Kingdom, showed that limb fracture was more common among males in age groups of 30-39 years old. But Among the oldest age group ( $>90$ years old) fracture was approximately twice as high in women as in men [15]. In line with this study, the current study showed that the prevalence of extremity fracture by sex for each age group showed that fracture was more common among males than among females in the younger age groups (up to 18-50 years old). The prevalence for 51-61 years old men and women were almost similar to each other. Among subjects 62-72 years and older, the prevalence of the fracture was higher in women than in men, and the difference increased with increasing age. Among the oldest age group (73+), the prevalence fracture was higher in females than males. This may be due to high outdoor activities in male and osteoporosis (due to decreasing estrogen and progesterone) in female in this age group.

The study showed that the majority of the respondents $88(61.1 \%)$ and $56(39.9 \%)$ were rural and urban respectively. Other study done in Addis Ababa revealed that the majority of the subjects $81.5 \%$ were urban residents whereas only $18.5 \%$ were from rural settings [12]. This difference may be due to high urban population in Adiss Ababa as compare to the study area. In this study showed that the probability of the occurrence of fracture in rural were more likely 2.491 times (AOR [95\% CI] 2.491(1.160, 5.347) as compare to urban. The this may be due to lack of awareness about traffic rules and high risk behavior (drinking alcohol leads to fighting each other) in rural area. In the current study, in the upper extremities, the majority of fracture occurred in the ulna 16(11.1), phalanges $15(10.5 \%)$, radius $14(9.7 \%)$, humerus $12(8.3 \%)$ and, in the lower extremities, the majorities of fracture occurred in femur 20(13.9\%), patella $18(12.5 \%)$ and tibia - fibula $16(11.1 \%)$. Study done in AAU, showed that the highest frequency of fracture 
occurred in the femur (15.8\%) followed by tibia-fibular (14.4\%) and humerus 26 (12.9\%). Isolated patellar fracture occurred in 22 $(10 \%)$, Ankle fracture accounted for (4.5\%) patients; Pelvic fracture was (3\%) patients [2]. Road traffic accident constitutes the largest proportion, $30(20.8 \%)$, among traumatic causes followed by fall down accident $23(16.0 \%)$ and hit by stick 22(15.3\%). RTA $30(20.8 \%)$ of which $70 \%$ and $30 \%$ occurred in urban and rural respectively. The most causes of fracture in male and female were RTA (22.8\%) and fall (21.2\%) respectively. Other study done in Adiss Ababa, on extremities fracture, there was an increase in severity of the fracture with age, and was open fracture $59.8 \%$. Roadtraffic accidents $37.5 \%$ and sport $30.9 \%$ accounted for most tibiodiaphyseal fracture with simple falls causing most fracture in the elderly [3]. This may be due to that RTA is the leading causes of fracture in both developed and developing countries.

The study done in Canada, alcohol intake was associated with an increased risk of fracture (risk ratio $[\mathrm{RR}]=1.23$; $95 \% \mathrm{CI}$, 1.061.43) [16]. In line with this, the current study showed that Patients who used alcohol chance of fracture was increased by the odds of 3.911 times (AOR [95\% CI] 3.911(1.473, 10.384) as compared to those who did not use. Patients who used alcohol and had fighting behavior the chance of extremity fracture were increased by the odds of 2.989 times (AOR [95\% CI] $2.989(1.408,6.348$ ) and 3.725 times (AOR [95\% CI] 3.725(1.319, 10.524) respectively.

\section{Limitation of the Study}

This study had limitations: the design of the study was cross sectional in this study. As a result, temporal relationships between factors and outcome variables cannot be established.

\section{Conclusion and Recommendation}

The prevalence of Extremities fracture was high at study area and socio-demographic characteristics, behavioral factors and comorbidity were found to be significantly associated with extremity fracture so that appropriate prevention strategies should be designed and implemented against extremity fractures.

\section{Data Availability}

The datasets used and/or analyzed to support the findings of this study are available from the corresponding author on reasonable request.

\section{Ethics approval and Consent to Participate}

The ethical clearance letter has been received from the research and review committee at Debre Marks University. Additionally, prior to beginning data collection permission was obtained from the hospital authority. Finally, an informed written consent was received from each participant mothers after explaining to them the research objectives. The participants were briefed on the study's purpose, procedures, potential risks, and benefits. In addition, the participants were told that failure to agree to or withdraw from the study would not change or endanger their access to treatment.

\section{Conflicts of Interest}

The authors state they do not have any conflicts of interest

\section{Authors' Contributions}

YMA developed the study design, interpreted the data, literature review, and prepared the manuscript initial draft. AG performed the statistical analysis, revised the entire section of the final manuscript critically and gave final approval of the version to be published. GC and MA participated in statistical advice, prepared the final draft of the manuscript and performed the necessary reference searches. All authors have read and approved the final manuscript.

\section{Acknowledgments}

The authors of this work would like to forward great and deepest gratitude for Jimma University, Debre Markos University, Debre Markos Referral Hospital staffs, data collectors and study participants.

\section{Bibliography}

1. Hollis AC., et al. "The epidemiology and treatment of femur fractures at a northern tanzanian referral centre". Pan African Medical Journal 22.1 (2015).

2. Admasie D., et al. "Radiological and clinical details of major adult limb fractures in a teaching hospital, AAU, Ethiopia". East and Central African Journal of Surgery 14.1 (2009): 88-97.

3. Admassie D., et al. "Brief communication: Adult limb fractures in Tikur Anbessa Hospital caused by road traffic injuries: Half year plain radiographic pattern". Ethiopian Journal of Health Development 24.1 (2010).

4. Meling T., et al. "Incidence of traumatic long-bone fractures requiring in-hospital management: a prospective age-and gender-specific analysis of 4890 fractures". Injury 40.11 (2009): 1212-1219. 
5. Lozano R., et al. "Global and regional mortality from 235 causes of death for 20 age groups in 1990 and 2010: a systematic analysis for the Global Burden of Disease Study 2010". The Lancet 380.9859 (2012): 2095-2128.

6. Amin S., et al. "Trends in fracture incidence: a populationbased study over 20 years". Journal of bone and Mineral Research: the Official Journal of the American Society for Bone and Mineral Research 29.3 (2014): 581-589.

7. Kombate NK., et al. "Epidemiology of Open Limb Fractures in a Country with Low-Income". Open Journal of Orthopedics 7.11 (2017): 356.

8. Gichuhi K. "Injury pattern among non-fatal road traffic crash victims". East African Orthopaedic Journal 1.1 (2007): 23-25.

9. Court-Brown CM., et al. "Fractures in older adults. A view of the future?" Injury 49.12 (2018): 2161-2166.

10. Pressley JC., et al. "Epidemiology of bone fracture across the age span in blacks and whites". Journal of Trauma 71 (2011): S541-548.

11. Kaye JA and Jick H. "Epidemiology of lower limb fractures in general practice in the United Kingdom". Injury Prevention: Journal of the International Society for Child and Adolescent Injury Prevention 10.6 (2004): 368-374.

12. Osman M., et al. "Magnitude and pattern of injuries in north Gondar administrative zone, northwest Ethiopia". Ethiopian Medical Journal 41.3 (2003): 213-220.

13. Beswick J. Working Long Hours HSL/2003/02. 2003.

14. Court-Brown CM and Caesar B. "Epidemiology of adult fractures: a review". Injury 37.8 (2006): 691-697.

15. Kaye J and Jick H. "Epidemiology of lower limb fractures in general practice in the United Kingdom". Injury Prevention 10.6 (2004): 368-374.

16. Kanis JA., et al. "Alcohol intake as a risk factor for fracture". Osteoporosis International 16.7 (2005): 737-742.

\section{Assets from publication with us}

- Prompt Acknowledgement after receiving the article

- Thorough Double blinded peer review

- Rapid Publication

- Issue of Publication Certificate

- High visibility of your Published work

Website: www.actascientific.com/

Submit Article: www.actascientific.com/submission.php

Email us: editor@actascientific.com

Contact us: +919182824667 